\title{
General Psychiatry Work-family conflict and job burn-out among Chinese doctors: the mediating role of coping styles
}

\author{
Ling Chen, ${ }^{1}$ Junjun Liu, ${ }^{2}$ Hailong Yang, ${ }^{3}$ Hui Ma, ${ }^{4}$ Hui Wang, ${ }^{5}$ Yun Huang, ${ }^{6}$ \\ Hao Cheng, ${ }^{7}$ Dianzhen Tang, ${ }^{8}$ Miao Liu, ${ }^{9}$ Houyuan Luo, ${ }^{10}$ Haitao Qu, ${ }^{11}$ \\ Diwen Shen, ${ }^{2}$ Ning Zhang ${ }^{4}$
}

To cite: Chen L, Liu J, Yang $\mathrm{H}$, et al. Work-family conflict and job burn-out among Chinese doctors: the mediating role of coping styles. General Psychiatry 2018;31:000004. doi:gpsych-2018-000004

- Additional material is published online only. To view please visit the journal online (http://dx.doi.org/10.1136/ gpsych-2018-000004).

LC, JL and HY contributed equally.

Received 26 September 2017 Revised 18 0ctober 2017 Accepted 15 March 2018

\section{Check for updates}

(c) Author(s) (or their employer(s)) 2018 . Re-use permitted under CC BY-NC. No commercial re-use. See rights and permissions. Published by BMJ.

For numbered affiliations see end of article.

Correspondence to Ning Zhang, Department of Clinical Psychology, Nanjing Brain Hospital Affiliated to Nanjing Medical University, Nanjing 210029, China; hubbub_kennel@163.com
Background Burn-out among doctors threatens their own health, and that of their patients. To identify risk factors of the doctor burn-out is vital to improving their health and increasing the quality of healthcare services. This study aims to explore the relationship between workfamily conflict (WFC) and burn-out among Chinese doctors and the mediating role of coping styles in this relationship. Methods A cross-sectional survey was conducted in China, with a questionnaire packet which consisted of the Chinese Maslach Burnout Inventory (CMBI), WFC Scale and the Simplified Coping Style Questionnaire (SCSQ). A total of 2530 doctors participated in the survey. Correlation analysis was performed to explore the relationship between CMBI, WFC and SCSQ scores. A linear regression model was set to determine the mediating role of coping styles on the relationship between WFC and burn-out.

Results Doctors who had higher scores on work interfering with family conflict, reported more emotional exhaustion $(r=0.514, P<0.001)$ and had a sense of accomplishment $(r=-0.149, P<0.001)$. Simultaneously, family interfering with work (FIW) was positively associated with all dimensions of burn-out $(r=0.213,0.504,0.088$, respectively, $\mathrm{P}<0.001)$. Coping styles had partial, complete and even mediating effects on the relationship between WFC and burn-out among Chinese doctors.

Conclusions WFC was correlated with burn-out, and coping style was a mediator in this relationship among Chinese doctors. Coping style was a positive resource against burnout.

\section{BACKGROUND}

Burn-out is defined as a syndrome of emotional exhaustion (EE), depersonalisation(DP) and reduced professional accomplishment $(\mathrm{PA})^{1}$ that occurs among various people-oriented professions like healthcare and social services. In the area of medicine, doctors are exposed to a range of harmful factors such as work overload, time pressures, role conflicts and effort-reward imbalance. The huge population base and increasing health consciousness over recent years have led to Chinese doctors being overburdened. Further, the relationship between doctors and patients often involves high interpersonal and emotional demands; this can also elevate the risk of burn-out. Doctors are considered a high-risk population with high levels of burn-out; what is more, they are more susceptible to depressive symptoms and suicide attempts, and they are often unable to satisfy the demands of patients. ${ }^{2-5}$

Work and family are two vital focal domains of adult life. Work-family conflict ${ }^{6}$ (WFC) is a bidirectional conflict that includes both work interfering with family (WIF) conflict and family interfering with work (FIW) conflict. The conflict may be time-based or strainbased. For example, when the amount of time devoted to the work role interferes with performing family-related responsibilities and vice versa. WIF is a form of inter-role conflict in which the general demands of time devoted to, and strain created by the job, interfere with performing family-related responsibilities, and FIW is a form of interrole conflict in which the general demands of time devoted to, and strain created by the family, interfere with performing work-related responsibilities. In China, most families are double workers, which means both male and female doctors have dual responsibilities for both work and family. WFC has found to be positively associated with burn-out, however, previous studies did not determine how WFC influences burn-out. ${ }^{7-11}$

Coping styles are thought of as stable strategies which may overcome or tolerate external and internal pressures or stressors. Some people cope with stress actively, while others cope passively. Active coping strategies are either behavioural or psychological responses designed to change the nature of stressors or one's opinion, whereas passive coping strategies lead people into activities (such as alcohol use) or mental states (such as withdrawal) which prevent them from directly addressing stressful events. Coping behaviours of individuals contribute to the explanation of why exposure to the same 
stressors may cause burn-out in some subjects, but not in others. $^{12} 13$

Doctors need to take care for themselves before they can provide care to their patients and customers. Given the high job stress, differences in coping styles, as well as imbalance between work and family, there is an urgent need to create an educational programme and strategies for the prevention of burn-out among doctors. To achieve this objective, it is important to elucidate the relationship between burn-out, WFC and coping styles among Chinese doctors. To our knowledge, there has been no integrative effort to examine coping styles as a mediator in the relationship between WFC and burn-out. In the present study, we examined the relationship between WFC and burn-out, and determined the mediating role of coping styles on the relationship between WFC and burn-out by using a cross-sectional survey of 2530 Chinese doctors.

\section{MATERIALS AND METHODS \\ Participants}

The presurvey results in Jiangsu Province showed that the prevalence of job burn-out among clinicians was $70 \%$ in 2008. Then we calculated the sample size using PASS software, and found a total sample of 2017 was needed. Stratified random sampling was conducted from 2009 to 2011, according to the division of the 2008 edition of the National Health Statistics Yearbook for the eastern, central and western regions. Each respondent held the Certificate of practising doctors granted by the Ministry of Health, People's Republic of China and was currently working in one of the hospitals as a registered doctor with a minimum service period of 1 year.

According to the results of random sampling, the eastern region, with the hospital as a unit, was directly sampled by our researchers who collected the questionnaires on the spot. Surveys for the central and western areas were mailed by special personnel responsible for receiving, measuring, recovering and returning. All surveyors received a unified training on methodology. In the process of measurement, the same guidance was given, and individual measurement and collective measurement were adopted. The questionnaires were reclaimed and stored.

A total of 3000 questionnaires were distributed and 2705 were returned (return rate: $90.2 \%$ ). One hundred and seventy-five questionnaires were discarded due to incomplete data, thus leaving 2530 analysable questionnaires. In order to protect the privacy of the subjects, the questionnaire was used anonymously. Each studied subject and the hospital were fully informed of the purpose of the study prior to enrolment and signed a consent form.

\section{Instruments}

Chinese Maslach Burnout Inventory

The Chinese Maslach Burnout Inventory Questionnaire and the cut-off values have been shown to be valid and reliable according to previous studies, ${ }^{12} 14$ and Cronbach's $\alpha$ coefficients of EE, Cynicism(CY) and Personal accomplishment (PA) were reported to be $0.874,0.801$ and 0.711 , respectively. A confirmatory factor analysis supported the three-factor structure $\left(\chi^{2} / \mathrm{df}=2.18\right.$, root mean square error of approximation (RMSEA) $=0.06$, root mean square residual $(\mathrm{RMR})=0.05$, normed fit index $(\mathrm{NFI})=0.89$, relative fit index $(\mathrm{RFI})=0.87$, incremental index of fit $($ IFI $)=0.94$, comparative fit index $(\mathrm{CFI})=0.93)$, which indicated good structural validity. EE mainly refers to the weary and worn out states that result from physical and emotional depletion; it is complicated in particular with emotional symptoms like fatigue, exhaustion and worrying that one's work will affect their own emotional states. DP mainly reflects an individual's poor social relationships and their evasive, negative and indifferent attitudes towards their work, which include manifestations like indifference to the feelings of their subjects, and refusing their subjects' requirements, self-assessment of their work achievements, such as a sense of incompetence, and a lack of efficiency, morale and achievement in their work.

Each dimension consists of 5 items, for a total of 15 items. The questionnaire used seven magnitudes to score each item: one representing 'completely fitting' and seven representing 'completely unfitting'. The dimension of reduced accomplishment (items 3, 6, 9, 12 and 15) used reverse scoring.

\section{The Simplified Coping Style Questionnaire}

Currently, evaluating an individual's coping style so as to understand its relationship with psychosomatic health has been considered to be an important study object of clinical psychology. A number of evaluation methods have been developed in foreign countries, such as the Ways of Coping Questionnaire (WCQ), which was compiled by Folkman and Lararus. Some scholars applied this scale in China, however, they found this scale was not suitable for use in the country because of cultural differences. So, with the aim of adjusting for Chinese culture the WCQ was revised by Xie YN. The Simplified Coping Style Questionnaire is a 20-item self-report that includes two dimensions. The first entry consists of 1-12 items, and focuses on reflecting the traits of active coping and passive coping (8-item). The second entry consists of 13-20 questions, and focuses on reflecting the traits of passive coping. The items were measured using 4-point Likert-type scales from 0 (never) to 3 (very often). Factor analysis results confirm the theoretical hypothesis, and previous studies have shown that this scale has good reliability and validity. The instrument has been commonly used in China. ${ }^{15-19}$

\section{The WFC Scale}

The WFC Scale consists of two subscales, WIF and FIW; the total scale consists of 18 items, and each of the two dimensions is measured by 9 items. Responses are made on a 5-point Likert-type scale. The WIF measures the 
Table 1 Demographics and work-related variables of the subjects and distribution of the Chinese Maslach Burnout Inventory

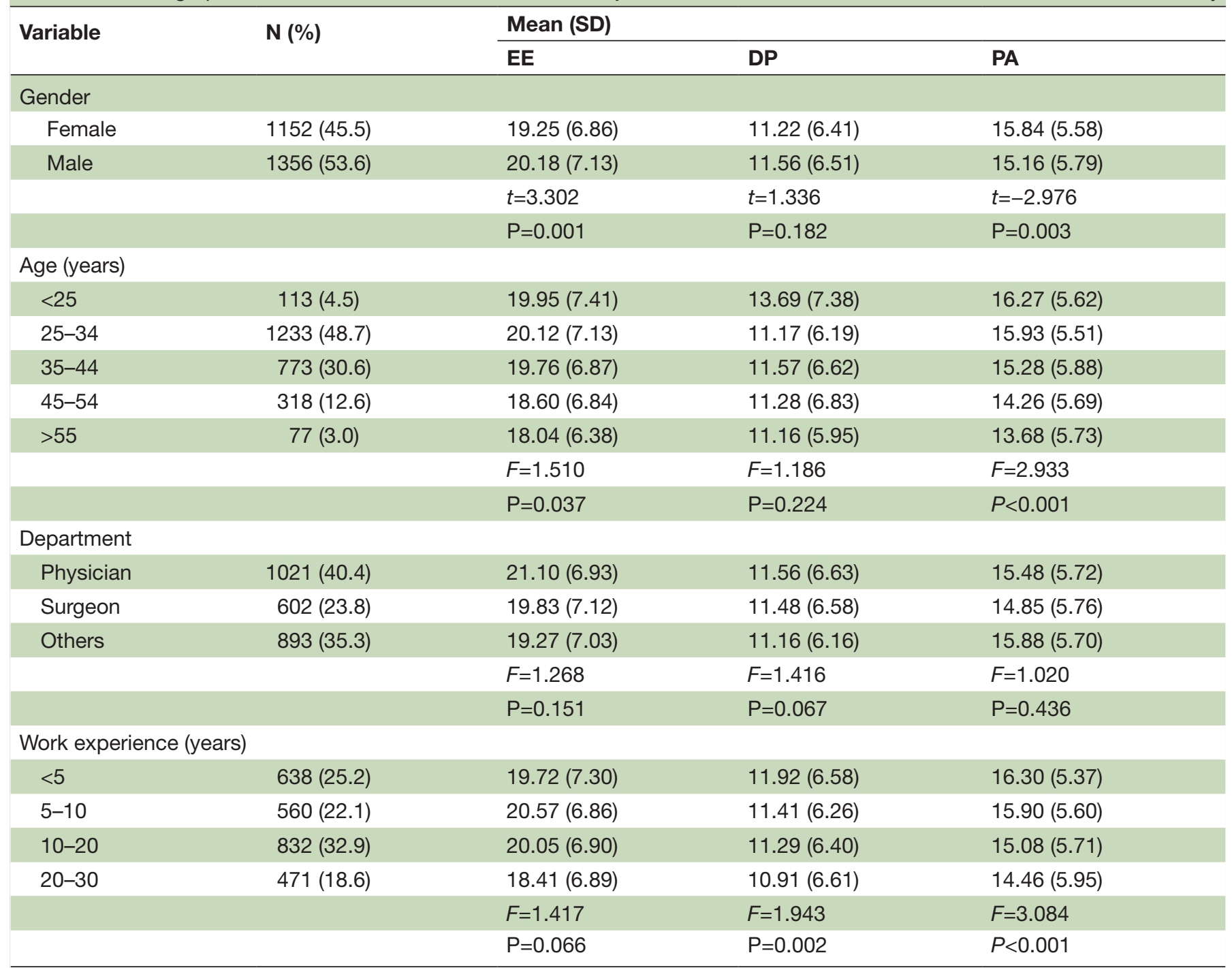

Gender is binary data. Age and work experience are continuous data which are in line with normal distribution.

${ }^{*} \mathrm{P}<0.05$.

${ }^{* *} \mathrm{P}<0.01$ (two-tailed).

EE, emotional exhaustion; DP, depersonalisation; PA,Personal accomplishment.

work-to-family direction of conflict. The FIW measures the family-to-work direction of conflict. The WFC was translated into Chinese, and its reliability and validity were reported in previous studies. This questionnaire and the cut-off values have been shown to be valid and reliable. 11020

\section{Statistical analysis}

All these data were obtained from a structured questionnaire. Demographic information including gender, age, work experience, and so on, was collected. The three dimensions of job burn-out were normally distributed by the Kolmogorov-Smirnov one-sample test (all $\mathrm{p}>0.05)$. T-test, analysis of variance and Pearson's correlation were performed to see the relationship between demographic information and instruments. Significant results were entered in the linear regression model of subscales of burn-out, individually. Finally, the mediation effect of coping styles was tested by Baron and Kenny's technique $/{ }^{21}$ Sobel test with the http:// www.quantpsy.org/sobel/sobel.htm website.

\section{RESULTS}

\section{Demographics}

The demographic and working characteristics of the subjects and the distribution of each dimension of burn-out in the categorical and grade items are shown in table 1. Mean (SD) of EE, PA differed significantly across age groups. Male doctors were more easily affected by EE and PA when compared with female doctors. Doctors with an age range ' $<25$ ' had the highest scores on EE. Doctors aged '35-44' were the most likely to be PA. The longer a doctor works, the more likely they are to have EE, but the higher their PA. There were 


\begin{tabular}{|c|c|c|c|c|c|c|c|c|c|}
\hline Variables & Mean & SD & 1 & 2 & 3 & 4 & 5 & 6 & 7 \\
\hline $1 \mathrm{EE}$ & 19.74 & 7.02 & 1 & & & & & & \\
\hline $2 \mathrm{DP}$ & 11.41 & 6.47 & $0.236^{\star *}$ & 1 & & & & & \\
\hline $3 \mathrm{PA}$ & 15.46 & 5.70 & $-0.087^{\star *}$ & $0.227^{\star \star}$ & 1 & & & & \\
\hline $4 \mathrm{WIF}$ & 17.09 & 4.75 & $0.514^{\star *}$ & -0.021 & $-0.149^{\star *}$ & 1 & & & \\
\hline $5 \mathrm{FIW}$ & 12.02 & 4.19 & $0.213^{\star *}$ & $0.504^{\star \star}$ & $0.088^{\star \star}$ & $0.123^{\star *}$ & 1 & & \\
\hline 6 Active coping & 23.64 & 5.66 & 0.033 & $-0.110^{\star \star}$ & $-0.272^{\star \star}$ & $0.175^{\star \star}$ & $-0.059^{*}$ & 1 & \\
\hline 7 Passive coping & 11.69 & 4.75 & $0.193^{\star \star}$ & $0.352^{\star \star}$ & $0.080^{\star \star}$ & $0.112^{\star \star}$ & $0.349^{\star \star}$ & $0.179^{\star \star}$ & 1 \\
\hline
\end{tabular}

${ }^{*} \mathrm{P}<0.05$,

${ }^{* *} \mathrm{P}<0.01$ (two-tailed).

EE, emotional exhaustion; DP, depersonalisation; FIW, family interfering with work; PA, decreased personal accomplishment; WIF, work interfering with family.

no significant differences of three dimensions of job burn-out between physician, surgeon and others.

\section{Pearson's correlation}

The results of Pearson's correlation analysis among subscales of WFC, coping styles and burn-out are shown in table 2. FIW was significantly correlated with all the dimensions of burn-out, which indicated that doctors with higher scores on the FIW Scale were more likely to burn out $(\mathrm{r}=0.213, \mathrm{r}=0.504, \mathrm{r}=0.088, \mathrm{P}<0.001)$. Meanwhile, the WIF Scale was positively associated with EE $(\mathrm{r}=0.514, \mathrm{P}<0.001)$, but negatively associated with $\mathrm{PA}$ $(\mathrm{r}=-0.149, \mathrm{p}<0.001)$, where doctors with lower scores on WIF were less prone to $\mathrm{EE}$, but more susceptible to PA. WIF was positively associated with active coping and passive coping $(\mathrm{r}=0.175, \mathrm{r}=0.112, \mathrm{P}<0.001)$, thus, the higher the scores on WIF, the higher the scores on passive coping. Whereas, FIW was negatively associated with active coping $(\mathrm{r}=-0.059, \mathrm{P}=0.012)$ but positively with passive coping $(\mathrm{r}=0.349, \mathrm{P}<0.001)$, while doctors with passive coping styles were found to have higher scores on FIW. Moreover, active coping styles had a negative impact on FIW ( $\mathrm{r}=-0.059, \mathrm{P}=0.012)$.

\section{The mediating role of coping styles on the relationship between WFC and EE}

As shown in table 3, WIF, FIW and passive coping were positively associated with $\mathrm{EE}(\beta=0.735,0.191,0.148, \mathrm{P}$ all $<0.001)$. The higher the score on the WFC Scale, the more passive coping style a doctor held, as well as the higher the chance of EE. Importantly, passive coping had a partial mediating effect on the relationship between WFC and EE, in that the regression coefficient for WIF ( $\beta$ from 0.731 to 0.735 ) and FIW ( $\beta$ from 0.257 to 0.191 ) was reduced when coping styles were added to the model. The result of the Sobel test confirmed the significant mediating effect of passive coping $(\mathrm{z}=10.86, \mathrm{p}<0.001)$.

The mediating role of coping styles on the relationship between WFC and DP

As shown in table 4, both FIW and passive coping style were positively associated with DP $(\beta=0.597, \beta=0.329$,
$\mathrm{P}<0.001)$ while active coping style was negatively associated with DP $(\beta=-0.133, \mathrm{P}<0.001)$. Coping style directly impacted the DP Score, and affected it indirectly by partially mediating the relationship between FIW and DP. The regression coefficient for FIW in relation to the DP Score was reduced from 0.738 to $0.597(\mathrm{P}<0.001)$ when coping styles were added to the regression analysis. The result of the Sobel test supported the significance of the mediating effect of active coping $(\mathrm{z}=14.24, \mathrm{P}<0.001)$ and passive coping $(\mathrm{z}=9.86, \mathrm{P}<0.001)$.

\section{The mediating role of coping styles on the relationship} between WFC and PA

The impact of coping styles on PA are shown in table 5 . WIF and active coping style were negatively associated with PA $(\beta=-0.133, \beta=-0.288, \mathrm{P}<0.001)$ while passive coping style was positively associated with PA $(\beta=0.178$, $\mathrm{p}<0.001$ ). More importantly, coping styles (active coping/ passive coping) indirectly affected PA by partially mediating the relationship between WIF and PA, and fully

Table 3 Results of hierarchical linear regression analyses, with $\mathrm{EE}$ as the criterion variable

\begin{tabular}{|c|c|c|c|}
\hline \multirow[b]{2}{*}{ Variables } & \multicolumn{3}{|l|}{ EE } \\
\hline & Step $1(\beta)$ & Step $2(\beta)$ & Step $3(\beta)$ \\
\hline Gender & $-0.850^{\star}$ & -0.509 & -0.533 \\
\hline Age & -0.379 & -0.239 & -0.263 \\
\hline Work experience & 0.245 & 0.180 & 0.174 \\
\hline WIF & & $0.731^{\star *}$ & $0.735^{\star \star}$ \\
\hline FIW & & $0.257^{* *}$ & $0.191^{* *}$ \\
\hline Active coping & & & $-0.070^{\star}$ \\
\hline Passive coping & & & $0.148^{\star \star}$ \\
\hline $\mathrm{R}^{2}$ & 0.004 & 0.278 & 0.287 \\
\hline$\Delta \mathrm{R}^{2}$ & 0.002 & 0.276 & 0.284 \\
\hline
\end{tabular}

${ }^{*} \mathrm{P}<0.05$.

${ }^{\star *} \mathrm{P}<0.01$ (two-tailed).

EE, emotional exhaustion; FIW, family interfering with work; WIF, work interfering with family, 
Table 4 Results of hierarchical linear regression analyses, with DP as the criterion variable

\begin{tabular}{|c|c|c|c|}
\hline \multirow[b]{2}{*}{ Variables } & \multicolumn{3}{|l|}{ DP } \\
\hline & Step $1(\beta)$ & Step $2(\beta)$ & Step $3(\beta)$ \\
\hline Age & 0.311 & 0.244 & 0.175 \\
\hline WIF & & $-0.118^{\star *}$ & $0.112^{\star *}$ \\
\hline FIW & & $0.738^{\star \star}$ & $0.597^{\star \star}$ \\
\hline Active coping & & & $-0.133^{\star \star}$ \\
\hline Passive coping & & & $0.329^{\star \star}$ \\
\hline $\mathrm{R}^{2}$ & 0.002 & 0.232 & 0.286 \\
\hline$\Delta \mathrm{R}^{2}$ & 0.001 & 0.231 & 0.284 \\
\hline
\end{tabular}

${ }^{* *} \mathrm{P}<0.01$ (two-tailed).

DP, depersonalisation; FIW, family interfering with work; WIF, work interfering with family.

mediating the relationship between FIW and PA in that the regression coefficient for WIF decreased when active coping/passive coping was added to the regression analysis (from $\beta=-0.180$ to $-0.133, \mathrm{P}<0.001$ ). The result of the Sobel test supported the significance of the mediation of active coping $(\mathrm{z}=24.89, \mathrm{P}<0.001)$ and passive coping $(\mathrm{z}=11.98, \mathrm{P}<0.001)$.

\section{DISCUSSION}

\section{Main findings}

As mentioned above, the main goal of this study was to explore the correlation between WFC, coping styles and burn-out dimensions among Chinese doctors, and demonstrate that WFC as a stress factor may may have both direct and indirect effects on burn-out. The main findings of our study are: (1) High scores on the WIF and FIW Scales may indicate EE, the higher the WFC Score, the more likely the person was to get EE. (2) FIW had a positive relationship with DP and PA while WIF had

Table 5 Hierarchical linear regression analyses, with reduced personal accomplishment as the criterion variable

\section{PA}

\begin{tabular}{lccc} 
Variables & Step 1 $(\boldsymbol{\beta})$ & Step 2 $(\boldsymbol{\beta})$ & Step 3 $(\boldsymbol{\beta})$ \\
\hline Gender & 0.443 & 0.409 & 0.499 \\
Age & -0.354 & -0.424 & -0.365 \\
Work experience & -0.362 & -0.323 & -0.394 \\
WIF & & $-0.180^{\star \star}$ & $-0.133^{\star \star}$ \\
FIW & & $0.149^{\star \star}$ & 0.045 \\
\hline Active coping & & & $-0.288^{\star \star}$ \\
Passive coping & & & $0.178^{\star \star}$ \\
\hline$R^{2}$ & 0.014 & 0.042 & 0.116 \\
$\Delta R^{2}$ & 0.012 & 0.039 & 0.113 \\
\hline
\end{tabular}

${ }^{*} \mathrm{P}<0.05$.

${ }^{* *} \mathrm{P}<0.01$ (two-tailed).

FIW, family interfering with work; PA, decreased personal accomplishment; WIF, work interfering with family. a negative relationship with PA. (3) Coping style was a mediating factor on the relationship between WFC and job burn-out in Chinese doctors.

There are several studies that have reported that demographic factors, such as age, education and marital status were associated with burn-out. ${ }^{22-25}$ In this study, burn-out subscale scores were significantly related with age which is in accordance with research.

Considering the relationship between WFC and burn-out, WIF and FIW were found to be positively related to EE among Chinese doctors. These results are in accordance with the results of previous studies. ${ }^{7-9}{ }^{26}$ Burke $^{27}$ et al found that WIF and FIW could lead to EE and $\mathrm{Wang}^{28}$ et al found that high values of WIF were significantly correlated to higher rates of personal burn-out. However, the effects of WIF and FIW on DP and PA were different. While FIW had a positive relationship with DP and PA, WIF had a negative relationship with PA. One explanation of the negative relationship between WIF and PA might be that employees who experienced interpersonal conflict and tension at work tended to focus more on their work activities to protect themselves from further tension and to be able to reach higher levels of performance, which may result in higher levels of professional accomplishment. This similar negative relationship was also observed in the investigations of Lambert. ${ }^{29}$ From another perspective, the different relationships of WIF and FIW with PA might be explained by the observation that doctors who experienced more WIF devoted more time and energy to work, whereas the dimension of professional accomplishment was mainly self-evaluated based on work roles rather than family roles; thus doctors who devoted more to work might achieve more professional accomplishments. By contrast, doctors who experienced more FIW devoted more time and energy to family, at the expense of work-related obligations. This might deprive doctors of opportunities to achieve more work accomplishments. To avoid doctor burn-out, the working environment must be improved and doctors should be given more material and emotional support, particularly when they must resolve conflicts between work and family. ${ }^{30-32}$

Positive factors related to the prevention of doctors' burn-out such as hardiness, active coping and social support were found to be the most important buffering factors. ${ }^{33}$ In the present study, active coping was negatively associated with DP and PA. These findings contribute to the understanding that coping styles have a significant effect on burn-out, and active coping may be a positive resource for combating burn-out. Our findings revealed that coping styles partially mediated the effects of WIF on $\mathrm{EE}$ and PA and coping styles also partially mediated the effects of FIW on EE, DP and completely mediated PA.

Doctors with a higher WFC might be more likely to use passive coping which in turn leads to higher levels of EE and DP. These findings should convince hospital administrators to be aware of the risk of WFCs among their doctors, and they should make efforts to develop 
strategies to decrease doctors' perceived WIF and FIW so as to reduce doctors' burn-out. For example, hospital administrators could recruit more staff and give doctors opportunities to enhance their technical skills to better fit in a high tech environment. Or hospitals may provide childcare services for doctors with young kids or arrange flexible schedules for breastfeeding doctors to release them from FIW. Compared with changing the WFC Score in doctors, it might be more positive and feasible for hospitals to conduct doctor training on problem-solving skills with the goal of helping doctors develop and employ active coping styles to deal with the stress they face at work. This type of training would be expected to improve doctors' health and well-being and to reduce professional burn-out, and thus improve the quality of healthcare. ${ }^{34}$

\section{Limitations}

Several limitations of the present study have to be mentioned. First, this study is cross-sectional in design. WFC, coping styles and burn-out were measured simultaneously, so causal conclusions cannot be drawn. All findings obtained in the current study should be confirmed by a longitudinal study. Second, all data were self-reported, which can introduce bias. Participants may have underestimated or overestimated the relationships between WFC and burn-out. Last but not the least, this study only focused on the relationship between WFC and burn-out and only checked some basic sociodemographic and working variables as confounders. More risk factors and their mechanisms should be investigated in further studies.

\section{Implications}

The present study demonstrated that WFC may be a possible predictor of job burn-out among Chinese doctors, indicating that doctors with a high WFC Score display more burn-out symptoms. More importantly, coping style might be an important factor which can affect burn-out directly or indirectly by partially or completely mediating the relationship between WFC and job burn-out. Our results suggest that when active coping strategies are adopted, burn-out is likely to be reduced. Conversely, the occurrence of passive actions is positively correlated with the chance of burn-out. Therefore, interventions focused on the improvement of coping strategies may be helpful in the prevention of job burn-out in doctors, so as to enhance medical service quality.

\section{Author affiliations}

${ }^{1}$ Department of Clinical Psychology, Jiangsu Province Geriatric Institute, Nanjing, China

${ }^{2}$ Department of Psychiatry, Nanjing Meishan Hospital, Nanjing, China

${ }^{3}$ Department of Clinical Psychology, Nanjing Drum Tower Hospital Clinical College of Nanjing Medical University, Nanjing, China

${ }^{4}$ Department of Clinical Psychology, Nanjing Brain Hospital Affiliated to Nanjing Medical University, Nanjing, China

${ }^{5}$ Department of Neurology Lianyungang Hospital of Traditional Chinese Medicine, Lianyungang, China

${ }^{6}$ Medical Insurance Audit Department, Medical Insurance Management and Service Bureau, Hangzhou, China
${ }^{7}$ Educational and Counseling Department of Mental Health, Nanjing University of Posts and Telecommunications, Nanjing, China

${ }^{8}$ Customer Service Department, Tuniu Corporation, Nanjing, China

${ }^{9}$ College of Education, Weifang University of Science and Technology, Huaifang, China

${ }^{10}$ Department of Educational Psychology, University of Alberta, Edmonton, Alberta, Canada

${ }^{11}$ Institute of Health Management, Jiangsu Jiankang Vocational College, Nanjing, China

Acknowledgements We would like to give our heartfelt thanks to all the doctors who participated in this study.

Contributors Conceived and designed this study: NZ, HW, HM, ML. Literature search and data collection: HC, HQ, DT, ML, YH. Data analysis: JL, HL. Drafting of the paper: LC, HY.

Funding The research special fund for public welfare industry of health grant (200802150) (JSYRKJ2010-C1-001; Jiangsu Provincial Medical Humanities and Social Science committee (No:JSYRKJ2010-C1-001); Philosophy and Social Science Special Project in Nanjing Medical University (No: 2013NJZS40); Key Project supported by Medical Science and Technology Development Foundation区Nanjing Department of Health (No. YKK17246, YKK16241).

Competing interests None declared.

Patient consent Obtained.

Provenance and peer review Not commissioned; externally peer reviewed.

Open access This is an Open Access article distributed in accordance with the Creative Commons Attribution Non Commercial (CC BY-NC 4.0) license, which permits others to distribute, remix, adapt, build upon this work non-commercially, and license their derivative works on different terms, provided the original work is properly cited and the use is non-commercial. See: http://creativecommons.org/ licenses/by-nc/4.0

\section{REFERENCES}

1. Li X, Guan L, Chang H, et al. Core self-evaluation and burnout among Nurses: the mediating role of coping styles. PLOS One 2014;9:e115799.

2. Maslach C, Leiter MP. Understanding the burnout experience: recent research and its implications for psychiatry. World Psychiatry 2016;15:103-11.

3. D'Ambrosio F. [Risk factors for burnout and job satisfaction in a sample of health professionals in Italy]. Ig Sanita Pubbl 2016;72:129-36.

4. Bondurant R, Morton N. Implementing change to reduce depression, suicide, and burnout among physicians-in-training. Mo Med 2016;113:16-18.

5. Gong Y, Han T, Chen W, et al. Prevalence of anxiety and depressive symptoms and related risk factors among physicians in China: a cross-sectional study. PLoS One 2014;9:e103242.

6. Zhou J, Yang Y, Qiu X, et al. Relationship between anxiety and burnout among chinese physicians: a moderated mediation model. PLoS One 2016;11:e157013.

7. Wang Y, Chang Y, Fu J, et al. Work-family conflict and burnout among Chinese female nurses: the mediating effect of psychological capital. BMC Public Health 2012;12:915.

8. Wang Y, Liu L, Wang J, et al. Work-family conflict and burnout among Chinese doctors: the mediating role of psychological capital. $J$ Occup Health 2012;54:232-40.

$9 \mathrm{Pu}$ J, Hou H, Ma R, et al. The effect of psychological capital between work-family conflict and job burnout in Chinese university teachers: Testing for mediation and moderation. J Health Psychol 2017;22:1799-807.

10. Hatam N, Jalali MT, Askarian M, et al. Relationship between familywork and work-family conflict with organizational commitment and desertion intention among nurses and paramedical staff at hospitals. Int J Community Based Nurs Midwifery 2016;4:107-18.

11. Bagherzadeh R, Taghizadeh Z, Mohammadi E, et al. Relationship of work-family conflict with burnout and marital satisfaction: crossdomain or source attribution relations? Health Promot Perspect 2016;6:31-6.

12. Saijo Y, Chiba S, Yoshioka E, et al. Effects of work burden, job strain and support on depressive symptoms and burnout among Japanese physicians. Int J Occup Med Environ Health 2014;27:980-92. 
13. Wu S, Li H, Zhu W, et al. Effect of work stressors, personal strain, and coping resources on burnout in Chinese medical professionals: a structural equation model. Ind Health 2012;50:279-87.

14. Margolis BL, Kroes WH, Quinn RP. Job stress: an unlisted occupational hazard. J Occup Med 1974;16:659-61.

15. Ding $Y$, Yang $Y$, Yang $X$, et al. The Mediating Role of Coping Style in the Relationship between Psychological Capital and Burnout among Chinese Nurses. PLoS One 2015;10:e122128.

16. Schütte K, Vocks S, Waldorf M. Fears, coping styles, and health behaviors: a comparison of patients with hypochondriasis, panic disorder, and depression. J Nerv Ment Dis 2016;204:778-86.

17. Li X, Guan L, Chang H, et al. Core self-evaluation and burnout among Nurses: the mediating role of coping styles. PLoS One 2014;9:e115799.

18. Schouws SN, Paans NP, Comijs $\mathrm{HC}$, et al. Coping and personality in older patients with bipolar disorder. J Affect Disord 2015;184:67-71.

19. Gutiérrez-Zotes A, Labad J, Martín-Santos R, et al. Coping strategies and postpartum depressive symptoms: A structural equation modelling approach. Eur Psychiatry 2015;30:701-8.

20. Wang Y, Liu L, Wang J, et al. Work-family conflict and burnout among Chinese doctors: the mediating role of psychological capital. $J$ Occup Health 2012;54:232-40.

21. Baron RM, Kenny DA. The moderator-mediator variable distinction in social psychological research: conceptual, strategic, and statistical considerations. J Pers Soc Psychol 1986;51:1173-82.

22. Maslach C, Schaufeli WB, Leiter MP. Job burnout. Annu Rev Psychol 2001;52:397-422.

23. Houkes I, Winants $\mathrm{Y}$, Twellaar M, et al. Development of burnout over time and the causal order of the three dimensions of burnout among male and female GPs. A three-wave panel study. BMC Public Health $2011 ; 11: 1-13$
24. Peisah C, Latif E, Wilhelm K, et al. Secrets to psychological success: why older doctors might have lower psychological distress and burnout than younger doctors. Aging Ment Health 2009;13:300-7.

25. Benson S, Sammour T, Neuhaus SJ, et al. Burnout in Australasian younger fellows. ANZ J Surg 2009;79:590-7.

26. Dyrbye LN, Shanafelt TD, Balch CM, et al. Relationship between work-home conflicts and burnout among American surgeons: a comparison by sex. Arch Surg 2011;146:211-7.

27. Burke RJ, Greenglass ER. Hospital restructuring, work-family conflict and psychological burnout among nursing staff. Psychol Health 2001;16:583-94.

28. Wang $\mathrm{Y}$, Chang $\mathrm{Y}$, Fu J, et al. Work-family conflict and burnout among Chinese female nurses: the mediating effect of psychological capital. BMC Public Health 2012;12:2904-36.

29. Lambert EG, Hogan NL. Work-family conflict and job burnout among correctional staff. Psychol Rep 2010;106:19-26.

30. Linzer M, Visser MR, Oort FJ, et al. Predicting and preventing physician burnout: results from the United States and the Netherlands. Am J Med 2001;111:170-5.

31. Awa WL, Plaumann M, Walter U. Burnout prevention: a review of intervention programs. Patient Educ Couns 2010;78:184-90.

32. Krasner MS, Epstein RM, Beckman $\mathrm{H}$, et al. Association of an educational program in mindful communication with burnout, empathy, and attitudes among primary care physicians. JAMA 2009;302:1284-93.

33. Saijo Y, Chiba S, Yoshioka E, et al. Effects of work burden, job strain and support on depressive symptoms and burnout among Japanese physicians. Int J Occup Med Environ Health 2014;27:980-92.

34. Mastenbroek NJ, Jaarsma AD, Demerouti E, et al. Burnout and engagement, and its predictors in young veterinary professionals: the influence of gender. Vet Rec 2014;174:144-144.

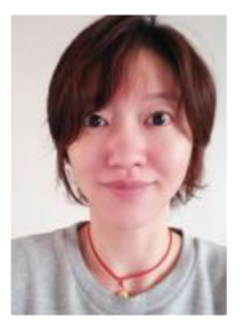

Ling Chen obtained a PhD from Nanjing Medical University, Nanjing, China, in 2011. She has been working at the Jiangsu Province Official Hospital since 2011, and now she is a resident doctor in the department of clinical psychology. Her research interests include Neuropsychiatry and Psychology. 